\title{
A propósito de La última cena, performance de Verónica Ruth Frías
}

\author{
Isabel Hurley \\ Galería Isabel Hurley (Málaga) \\ isabel@isabelhurley.com
}

I/ Cenacolo o L'Ultima Cena que Leonardo da Vinci pintó en el refectorio del convento dominico de Santa Maria delle Grazie, en Milán, a finales del siglo XV, por encargo de Ludovico Sforza, supuso la superación de las representaciones que de este pasaje del Nuevo Testamento se habían hecho hasta entonces. La iconografía, que se remonta al arte paleocristiano, conserva dos ejemplos del siglo XIII -frontal del Maestro de Soriguerola y mosaicos de San Marcos de Venecia-, donde ya se apunta la disposición lineal, pero sus referentes inmediatos son los del refectorio de Sant'Apollonia de Andrea del Castagno (1447) y los de Ghirlandaio para la Abadía benedictina de Passignano (1476), para la iglesia de Ognissanti (1480) y para el también convento dominico de San Marco (1486). Leonardo rompe con los esquemas compositivos precedentes al situar la escena en un momento posterior, una vez los apóstoles son informados de la traición, con el consiguiente revuelo que la noticia produce. Por ello, dota a la composición, que se abre al fondo por medio de tres ventanas a un paisaje típicamente toscano, de un dinamismo y variedad de movimientos y fisonomías antes desconocidos, resultando de una naturalidad y modernidad asombrosas. Los personajes han sido despojados de las aureolas de santidad y aparecen en cuatro grupos de tres, que algunos identifican con las triadas platónicas vistas por las corrientes neoplatónicas florentinas, sobre todo Marsilio Ficino y Pico della Mirandola. Esta circunstancia y la silueta que dibuja su disposición han dado lugar a especulaciones de tipo esotérico no demasiado fundamentadas. Judas ya no está en solitario al otro lado de la mesa y Juan no aparece dormido sobre el hombro o el regazo del Maestro, que se aísla en el centro, concentrado en sus últimas horas, y concentrando en su cabeza todas las líneas de fuga. La composición se encuadra en una arquitectura que materializa el antropocentrismo inspirador del renacimiento italiano y en la que parece aplicar lo aprendido mientras ilustraba De Divina Proportione. En este tratado coetáneo, Lucca Pacioli habla de la naturaleza divina de la geometría y las matemáticas e, incomprensiblemente y salvando las distancias, anticipa los módulos fractales y el concepto de rizoma que desarrollan Gilles Deleuze y Felix Guattari, asimismo anticipado por Borges en El jardín de los senderos que se bifurcan, de 1941. Por si fuera poco, algunos parecen advertir en la atmósfera enrarecida que ambienta inmaterialmente la escena la primera tentativa de perspectiva aérea. Podría explicarse por las numerosas intervenciones posteriores para frenar o reparar el deterioro que experimentó la obra desde pocos años después de su finalización. El uso experimental de nuevos aglutinantes y de una combinación de óleo y temple sobre yeso seco, en lugar de la tradicional del fresco sobre yeso húmedo empleada hasta entonces para las pinturas murales, favorecieron el crecimiento de hongos y la descamación, por lo que no se sabe a ciencia cierta qué nos ha llegado de la factura original.

Verónica Ruth Frías toma prestada la escenografía del famoso fresco, si bien sustituyendo las figuras masculinas por otras femeninas. Ahora solo hay apóstolas, mujeres que desempeñan diferentes cometidos en el ámbito cultural de la ciudad, algunas de ellas también madres. Esto supone otro punto de inflexión en un arquetipo que recientemente ha experimentado no pocas variaciones, muchas de ellas nada ortodoxas, sobre la ya canónica de Leonardo. Recordamos algunas memorables, como la de Buñuel en la cena de los desharrapados de Viridiana; las diversas que hizo Andy Warhol en clave pop o la también fotográfica de David Lachapelle, rejuvenecida y recodificada según la jerga de tribu urbana; la cinematográfica y del todo irreverente que ofreció Robert Altman en Mash; la publicitaria para Marithe Françoise Girbaud; la teatral para la puesta en escena de la obra de Pynchon 
The Inherent Vice; y en el campo de la animación las de Los Simpson o South Park, por citar unas pocas. Aunque más lejana en el tiempo, la muy atrevida de Cranach el Joven, que dispuso en el lugar de los Apóstoles a las cabezas visibles de la Reforma y al Príncipe Elector de Sajonia, ataviados y ambientados según correspondía a su momento y rango. Teniendo en cuenta que es en esta ocasión cuando se instituye el Sacramento de la Eucaristía y, por tanto, el Dogma de la Transubstanciación, no aceptado por la Iglesia luterana, tuvo una ocurrencia de lo más transgresora.

A Leonardo le corresponde el honor de ser el primero en abordar el concepto del arte como obra mental, intelectual, lejos de la dimensión mecánica que se le otorgaba en el Tratado de Cennino Cennini, más acorde al estatus de artesano que tenían tanto pintores como escultores. Verónica reflexiona y hace reflexionar con esta performance sobre la situación de la mujer en el mundo actual, empoderándola, al tiempo que ofrece la versión mas poliédrica, a la vez que cotidiana y cercana de su predecesor. Y no sólo de su obra como artista y creador de todo tipo de artefactos y máquinas, sino también como activista en la reivindicación de los derechos de sus colegas artistas, el primero de los cuales era ser considerados como tales, apelando a la naturaleza intelectual de su profesión, muy por encima de la intervención manual requerida en el proceso. La obra de Verónica Ruth Frías es un hermoso e implacable alegato sobre el inaplazable reconocimiento del trabajo de las artistas mujeres y del lugar que les corresponde junto a sus colegas varones.

Preguntada por Cindy Nemser sobre el papel de la mujer en el arte, para un artículo en Arts Magazine, en 1972, Louise Bourgeois dijo: «una mujer no tiene lugar como artista hasta que no prueba una y otra vez que no será eliminada». El que Louise Bourgeois, la mujer que más alto ha llegado en el mundo del arte en toda la historia, diera esta respuesta es más que significativo. De hecho, hasta 1982 no expuso en el MoMA, con la ayuda de una beca del National Endowment for the Arts; tenía 70 años. Fue gracias a comisarios y críticos afines al movimiento feminista que se fue produciendo la puesta en valor de esta artista, que hasta entonces era prácticamente una desconocida para el gran público y menospreciada por la mayoría de la crítica y los intereses de las grandes instituciones. En la hoja de sala se reconoce cómo hasta poco antes no se había valorado su trabajo en la justa medida: «[...] for many years working outside the mainstream of American art, is finally recognized as one of this country's most important artists. [...] While her work had been seen with regularity in group shows, her solo shows were infrequent». La muestra fue comisariada por Deborah Wye y Alice Legg y, en paralelo, tuvieron lugar dos conferencias, una de las cuales fue pronunciada por Lucy Lippard, quien en 1975 había publicado en Art Forum el artículo «Louise Bourgeois: from the inside out».

En «Gender and Possession» -Art in America, 1 de abril de 1983- Robert Storr, a propósito de su reciente retrospectiva en el MOMA -la primera dedicada a una mujer en esta institución, que, por cierto, ya contaba con dos de sus piezas-, reconoce su consideración reciente como una outsider, asegurando que, según los estándares del momento, no había tenido en modo alguno lo que se entendía una carrera dentro del mundo del arte.

Louise Bourgeois participó en 1972 en la mesa redonda, «Does Art have a Gender?» para el foro de debate sobre el papel de las mujeres en el arte, Forum: Women in Art, también organizado por Cindy Nemser, donde se abordaba otro de los temas mas cuestionables del apartheid sufrido por las mujeres dentro del sistema del arte. Lucy R. Lippard formulaba al respecto una cuestión similar, "What is Female Imagery?». Es Linda Nochlin quien se apresta a responder indignada que la mera pregunta es restrictiva porque ella es un ser humano no sujeto a las restricciones construccionistas del sistema androcentrista/patriarcal, aunque tras meditarlo reconoce que el creador está condicionado por su experiencia. Todo ello sin aceptar que el género biológico o el constructo cultural de identidad de género puedan determinar una producción que desea inscribirse en una categoría abierta y más amplia. Parece que el ambiente distaba mucho de frecuentar los tópicos que establecían como propios de lo femenino aquellos temas más amables y decorativos, o aquellas producciones vehiculadas a través de técnicas artesanales, consideradas una forma de arte limitada y/o simplemente ornamental, pero que fueron adoptadas por las mujeres artistas como estrategia de crítica identitaria. En conclusión, géneros y disciplinas menores e impropios del Arte con mayúsculas producido por los hombres.

En la década de los setenta del siglo pasado se clamaba por la eliminación del «techo de cristal» y la necesaria reescritura de la historia del arte, muy especialmente de los últimos doscientos años. A título anecdótico, cabe citar una 


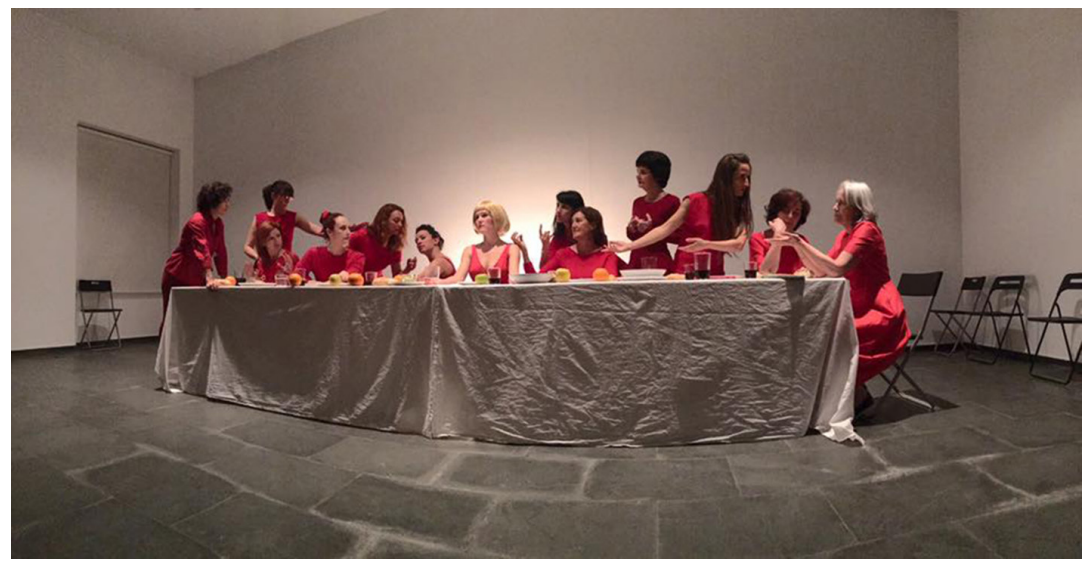

Performance de Verónica Ruth Frías en la Galería de Isabel Hurley, 2017

rareza editorial anónima, de la Imprenta de Aguado, con fecha de 1827, El té de las damas. El narrador, varón, explica cómo en una casa principal de la Corte se reúnen a tomar el té un grupo de señoras, más o menos instruidas y aficionadas a la lectura pero sin capacidad intelectual suficiente para redactar por ellas mismas el relato:

\begin{abstract}
Harto hablan los hombres de sí, dicen: todo lo mandan, disponen y gobiernan: todo es por ellos y para ellos: por lo común somos sus esclavas: algunas veces se nos permite ser sus iguales, pocas sus superiores [...] de aquí resulta que la mayor parte de los libros son escritos por ellos, con lo que ocupan muchas veces el único lugar [...] ahora que aquí reunidas disfrutamos de nuestra libertad, venguémonos de su indiferencia o injusticia, y sea nuestro sexo el preferido; hablemos sólo de el.
\end{abstract}

Aunque algo se avanzó en ese tiempo, no es suficiente la mayor visibilidad permitida, y el empleo de esta palabra es bien expresivo de la actual situación. Griselda Pollock advierte que el canon de la historia del arte es uno de los más virulentos y «virilentos», por lo que propone un cambio del modelo patriarcal que establece el sexismo estructural, asimismo vinculado a la discriminación de clase y raza. A este patrón responde la construcción de los paradigmas de sexo que dividían los espacios de actuación, otorgando al varón lo público y relegando a la mujer el de lo privado-doméstico. En Femme-maison, serie de trabajos de Louise Bourgeois de 1946-47, en los que la cabeza de la mujer es sustituida por la imagen de una vivienda, denuncia su condición de prisionera oculta en su propia casa: «la identidad femenina es absorbida y oscurecida por el reino doméstico que nutre y soporta al mismo tiempo»; mensaje también contenido, aunque no en exclusiva, en la serie Celdas (1986-2008). En sus memorias, Victoria Ocampo confiesa la indignación que le produjo y marcó para siempre la frase grabada en el anillo de bodas de su abuela por deseo expreso de su prometido: «encadenada y feliz». De sobra es conocida la existencia del estrado en las viviendas españolas, documentada desde el siglo XIII (ilustraciones en el Libro de Ajedrez, Dados y Tablas y Cantigas de Alfonso X El Sabio, pinturas de Berruguete, Roelas o Zurbarán, o en escritos de Cervantes, Lope de Vega, María de Zayas o Mme. D’Aulnoy). Este era el espacio reservado a las mujeres, que, si bien, y según algunos autores, suponía un ámbito de su dominio (puede que las reuniones de aquellas damas para tomar té tuvieran lugar en uno de ellos), no menos cierto es que implicaba reclusión y exclusión. Con posterioridad, la sala de estar de la vivienda burguesa será aquel rincón en el que hace su vida la mujer y donde se encuentran los útiles de trabajo propios de su sexo, como las labores. En el recibirían los hijos las lecciones de parte de sus profesores y compartiría su tiempo entre lo uno y lo otro hasta la llegada del esposo. O el gabinete tocador, en el que, como escribió M. ${ }^{a}$ Pilar Sinués en El ángel del hogar, cuya primera edición se hizo en Madrid, en 1881: «a esposa seguiría con secreta y profunda amargura, los estra- 
gos que el paso de los años va causando en sus lozanías y esplendores y se embellecerá para aquellos que la quieren, aquellos que sentirán una piadosa amargura ante el derrumbamiento de sus encantos».

En ese reparto también se decidían los roles a desempeñar y el de la mujer no iba mucho mas allá de ser una obediente esposa, buena ama de casa y madre entregada. Siguiendo con M. ${ }^{a}$ Pilar Sinués, pese a su condición de intelectual, periodista y novelista, muy afamada en su tiempo: «el esposo, tras la interminable lucha diaria en el mundo exterior, agradecerá sobremanera encontrarse al volver a casa a una compañera en condiciones; vuestro urgente negocio es agradar a vuestro esposo, conservar su ternura y repartir a vuestro alrededor un perfume de poesía que le embriague dulcemente y le impida pensar en ninguna otra mujer».

Cualquier inquietud o vacación que la distrajera de estos cometidos sería duramente censurada o, como mucho, tolerada, siempre y cuando, en el caso de las familias burguesas de alta capacidad económica, se limitara a un mero pasatiempo como demostración de una distinguida crianza a la hora de entretener a las visitas. En realidad, un atributo más de la buena disposición para agradar al marido y sus invitados, una veleidad, casi uno mas de los afeites permitidos para realzar sus encantos. Hasta no muchos años atrás, el aprendizaje se haría entre las paredes del hogar, nunca mediante estudios oficiales y no se ejercitará de manera profesional, ya que toda actividad remunerada quedaba reservada a los varones.

Es más, cualquier atisbo de inteligencia molestaba y hasta repugnaba. En opinión de Marchán Fiz La deshumanización del arte sigue siendo un texto de referencia básico para abordar nuestra tradición de lo nuevo. De hecho, afirma que la filosofía de Ortega es fundamental para la teorización de las vanguardias españolas, europeas y hasta americanas. Sin embargo, y pese a que tuvo que rendirse al talento de Victoria Ocampo y Maruja Mallo, para Ortega y Gasset el papel de la mujer en la sociedad consistía en estar no en hacer, como era el del hombre, al que había de servir de inspiración y estímulo para hacer mas y mejor. En Paisaje con una corza al fondo (1927) recoge la opinión que sobre las mujeres de un tal Olmedo, amigo suyo, a quien describe como hombre admirable e inteligente, y que confiesa sin pudor sentir repugnancia por la mujer de talento a no ser «que un exceso de razón sea compensado por otro de sinrazón, porque la mujer demasiado racional le olía a hombre». El mismo Ortega escribió que la mujer es un ser confuso y que es «una forma de humanidad inferior a la varonil», que, por supuesto, «está hecho de claridades». Esta visión era compartida por la mayoría de las mujeres educadas en esos parámetros machistas. Griselda Pollock cita la frase de Bettina Van Houten: "La mujer de genio no existe. Cuando existe es un hombre», a modo de paradigma del machismo femenino de finales del siglo XIX.

Estas afirmaciones y muchas más respaldan los comportamientos que en perjuicio de las mujeres profesionales se han producido en todos los ámbitos, y no solo potenciados por los hombres, sino por aquellas madres que los han inculcado a sus hijos, mujeres y varones, educándolos en roles sexistas bien diferenciados.

Linda Nochlin se preguntaba «¿Por qué no han existido grandes mujeres artistas?». En este texto de 1971 -en España no salió traducido hasta 2008, e incompleto-, pionero en la aproximación al problema, afirmaba que la situación de las mujeres en el sistema del arte contemporáneo o del mundo laboral en general, no es el problema. A modo de comparación argumentaba que el mal llamado problema judío por la Alemania nazi no era tal problema, muy al contrario, la Alemania nazi es lo que constituyó un problema para los judíos y no nazis de ese país y de buena parte del mundo. El problema está en todo aquello que genera esa discriminación indeseable e irracional y eso es lo que hay que transformar. La categoría de un discurso elaborado para sostener aquella ideología que perpertúa el dominio del varón. $Y$ en lo que a las mujeres artistas se refiere extiende un velo de sospecha sobre su profesionalidad, determinación, continuidad, calidad, revalorización, etc; todo lo que puede verse afectado por la muy difícil o hasta imposible conciliación entre hogar y trabajo.

Volviendo a la obra de Verónica Ruth Frías, no pasan desapercibidas sus varias lecturas. Las participantes proceden de diferentes ámbitos del mundo laboral/cultural, donde las circunstancias no son muy distintas, muchas de ellas ejerciendo también las respectivas profesiones en una situación de difíciles conciliaciones con sus responsabilidades en el entorno doméstico, como madres, esposas e hijas. La performance comienza con una escena estática que mimetiza las poses de la obra de Leonardo y donde todas las performers, vestidas de rojo, permanecen inmóviles, impasibles 
y expectantes. Esta quietud reflexiva da paso, en un momento dado, al movimiento y desorden provocado por la entrada de las hijas de aquellas participantes que son madres, rompiendo el estatismo, el orden -istatu quo?-, el silencio y la paz que reinaba hasta ese momento, e irrumpiendo la frescura y lo cotidiano de una escena doméstica en uno de los momentos mas distendidos de la vida familiar, como es compartir los alimentos en la mesa. Tocamos aquí un tema crucial y desolador: el de la violencia de género -física y psicológica- ejercida contra las mujeres en todos los ámbitos donde está presente, y también contra sus hijos. Frente a este drama, urge clamar día tras día sin desmayo. La Última Cena es narrada en el Nuevo Testamento como el episodio en el que Jesucristo se reunió con sus amigos antes de entregarse al sacrificio. El color de las prendas que visten las performers nos evoca la violencia y la sangre derramada por miles de mujeres, muy a menudo en presencia de sus hijos.

María Ruído, en su libro Ana Mendieta (2002), sobre la artista cubana, comprometida en vida y obra con la causa de las mujeres, casada con Carl André -a quien el MNCARS ha organizado dos exposiciones, mientras que a ella ninguna- y muerta en circunstancias parece que no muy claras, escribe: «Esto no ha cambiado demasiado. El relato de lo que significa ser artista sigue siendo patriarcal y sigue respondiendo a unos códigos donde las mujeres no salen en la foto. $Y$ no se trata de hacer una historiografía paralela sólo de mujeres artistas, sino de destruir el marco en el que se construye la historia del arte». Mendieta cayó por una ventana del piso 33, tras una fuerte discusión con su marido, sobre el que recayeron sospechas bien fundadas de ser el autor del lanzamiento. El conserje del edificio declaró que gritaba «NO» mientras caía. Lamentablemente, no ha sido el único caso de discriminación y maltrato de mujeres artistas por sus colegas. No hace mucho que Georg Baselitz, casado con una pintora, cuestionaba la fuerza de la pintura hecha por mujeres.

El mes de marzo ha sido proclamado Mes Internacional de la Mujer por organismos internacionales dependientes de la ONU, como la FAO, y por numerosas instituciones de diferentes países, caso de Estados Unidos, pese a su actual presidente, y así lo avalan las publicaciones aparecidas en las páginas de sus embajadas. Antonio Guterres, Secretario General de Naciones Unidas, con motivo de la última celebración del Día Internacional de la Mujer Trabajadora se

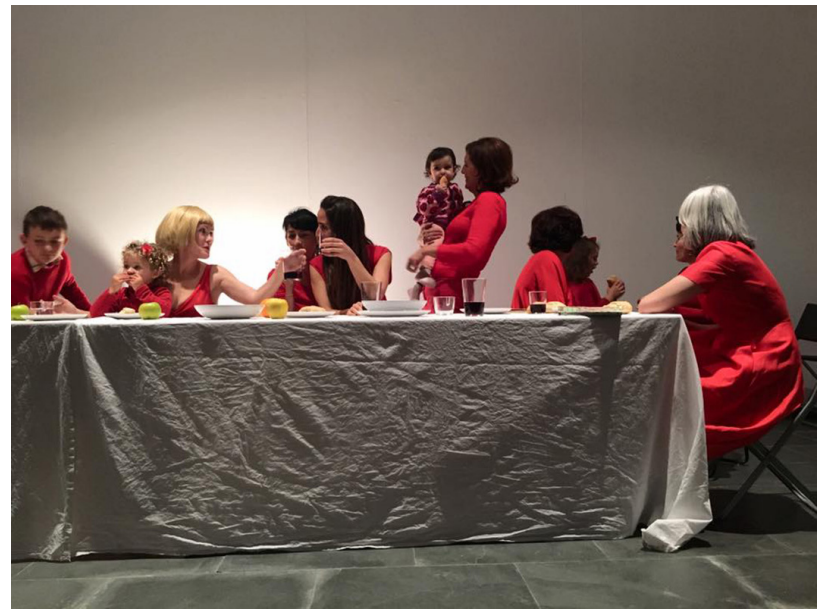

Performance de Verónica Ruth Frías en la Galería de Isabel Hurley, 2017

ha expresado en los siguientes términos: «En el Día Internacional de la Mujer, debemos comprometernos a hacer todo lo posible para superar los prejuicios arraigados, apoyar la participación y el activismo y promover la igualdad de género y el empoderamiento de la mujer».

Según los datos proporcionados por el Ministerio de Interior, desde 2007, en menos de diez años, solo en España han muerto 689 mujeres víctimas de la violencia machista. En 43 años, la banda terrorista ETA asesinó a 829 personas. La proporción eleva casi al cuádruple las cifras del

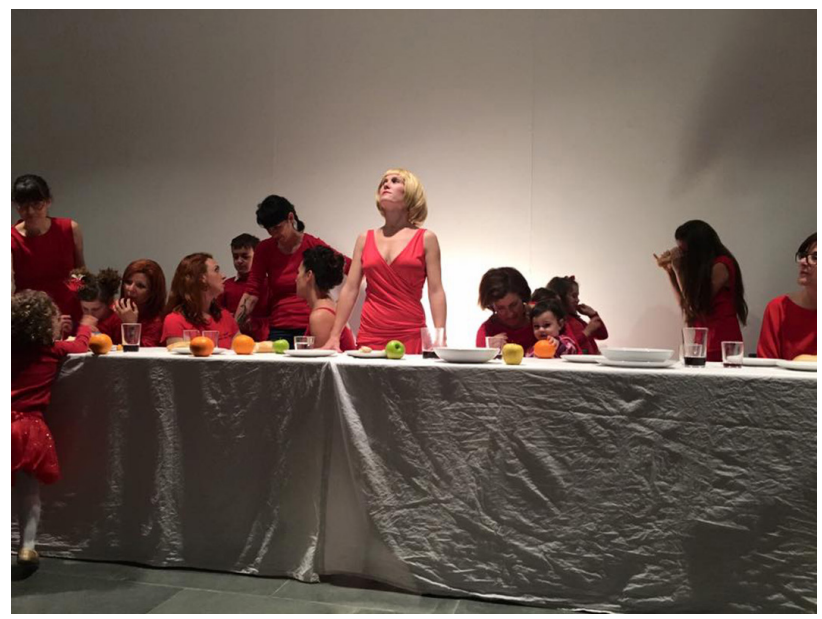

Performance de Verónica Ruth Frías en la Galería de Isabel Hurley, 2017 
horror cometido por los terroristas domésticos, que ante la supuesta amenaza que, al parecer, les supone la conquista de lo público por sus parejas, hecho intolerable para ellos, deciden expulsarlas de todo ámbito por la vía del feminicidio.

La Carta de Derechos de Naciones Unidas reconoce la igualdad entre sexos, sin embargo los «techos de cristal» aún no han terminado de caer, como no lo ha hecho el velo de ignorancia y brutalidad de los maltratadores.

Las Guerrilla Girls planteaban en una archiconocida pieza de 1989 Do women have to be Naked to get into de Met. Museum? A continuación denunciaban que solo había un 5\% de mujeres artistas frente a un 85\% de obra con desnudos femeninos. En la actualización que hicieron de la misma pieza en 2004, sorprendentemente, la proporción era aún peor: un 3\% frente al 83\%. Patricia Mayayo escribe al respecto que las mujeres: «son hipervisibilizadas como objeto de la representación y al mismo tiempo invisibilizadas como sujeto creador». Otra cuestión de no menor interés es los modos en que se las representa.

La permanencia de unas estructuras y medios de comunicación androcéntricos y la comunión con su ideología de la casi totalidad de sus dirigentes y de los artistas por ellos seleccionados ralentiza o impide que se cambien los modelos de producción cultural, aunque haya habido excepciones. El New Museum of Contemporary Art, fundado y dirigido por Marcia Tucker, apoya una más amplia comprensión del fenómeno artístico en base a modelos provenientes del feminismo, con estructuras alternativas ajenas al sistema del arte, que potencian la colaboración de individuos cuyos puntos de vista son completamente diferentes.

Juan Luis Moraza, en la ponencia que pronunció en el MACBA, en el marco de las actividades programadas con motivo de la exposición de Martha Rosler, ofrece una serie de datos y reflexiones que inciden en la cuestión esencial del problema y apunta a la solución desde su punto de vista, que no puede ser otro que el de un hombre y, sin embargo, coincidente con lo esbozado por muchas de las mujeres que mas ahondaron en la cuestión. Comienza recordando cómo The Economist publicó en 1996 varios artículos bajo el título "The Trouble with Men. Tomorrow's Second Sex», poniendo de manifiesto el "pánico creciente ante una imprevista e inminente supremacía femenina: supremacía en las aulas, donde el índice de fracaso escolar comenzaba a ser superior entre los chicos y el rendimiento mayor entre las chicas; supremacía en el trabajo, donde los trabajos industriales dejaban paso a los servicios (administración, comunicación, finanzas, enseñanza, etc.) y donde las mujeres comenzaban a despuntar; supremacía en la familia, donde la figura del padre y el abandono masculino estaban debilitando la estructura; y supremacía psicológica, pues la desmoralización, la renuncia a la búsqueda del éxito, la adición, el nihilismo, la delincuencia o la muerte temprana comenzaban a ser síndromes masculinos». En resumen, se hacía pública la decadencia del mito de la masculinidad.

Aceptado que lo masculino y lo femenino son constructos socioculturales, ya que hombres y mujeres participan de ambos, M. Wittig califica ambas categorías de artificiales y niega, incluso, su condición de mujer como la niega en toda aquella que no se encuentra en una situación de dependencia con respecto a un hombre. Juan Luis Moraza, por su parte, asegura que, como Maiakovsky, más que hombre se siente una nube en pantalones. Más adelante cita a Sadie Plant, quien advierte que la identidad disociativa es propia de nuestra época. Salvando las distancias, Aristófanes se adelantó a estos planteamientos en su discurso para El Banquete de Platón. Allí describió cómo los seres humanos habían gozado originalmente de la fortaleza de dos individuos unidos, en unos casos de diferente sexo y en otros de dos criaturas del mismo, hombres o mujeres, separados mas tarde por los dioses ante el temor que les producía su naturaleza poderosa. Desde entonces cada individuo busca su otra mitad. Pensemos sobre ello.

Continúa J. L. Moraza:

La cultura popular actual, a través de la imagen publicitaria, cinematográfica o literaria, ha generado progresivamente una iconografía, perfectamente legitimada en un discurso victimario, que, invirtiendo los papeles, reproduce los mismos patrones dualistas que el feminismo inteligente ha pretendido deconstruir y abolir El tardocapitalismo ha advertido la rentabilidad política de este tipo de discurso sexista, perfectamente legitimado, políticamente correcto, y sólo en apariencia feminista. El juego de identificaciones posibles e imposibles intensifica las diferencias y luchas de género contribuyendo a reenunciar los tópicos esencialistas sobre «hombre» $y$ «mujer", y provoca un malestar que, a falta de otros cauces, se resuelve de forma violenta en absurdos intentos de identificación masculina con fantasmas de virilidad trasnochados. 
Gracias en buena medida al feminismo (y a otros movimientos de emancipación social, política, racial, etc.), la cultura contemporánea se enfrenta a situaciones de negociación impensables hasta hace bien poco tiempo. $Y$ en virtud de esas situaciones, existen temas que incumben mutuamente a hombres y mujeres. Si las mujeres son seres evolucionados, sofisticados, tras cien años de trabajo y discusión sobre su identidad mientras los hombres se embrutecen, se atrincheran en roles desgastados y deslegitimados de masculinidad, el resultado será como está siendo en muchas ocasiones una descompensación que genera conductas y actitudes maniqueas y violentas.

Este párrafo no deja resquicio para la duda en cuanto a la coincidencia de intereses por parte de hombres y mujeres en afrontar un diálogo valiente y comprometido. Son otros elementos los que impiden compartir la mesa de negociación social y alcanzar el deseado pacto.

No se trata de hacer tabla rasa sobre la genética y la herencia cultural; el hecho de reconocer lo masculino y lo femenino resultado de ambas circunstancias no implica que no existan diferencias ni que se desee ignorarlas. La cuestión es que no se justifique con la diferencia la desigualdad. Se trata de encontrar un espacio de encuentro que exige la necesaria y honesta colaboración de quienes detentan el poder, muchos de los cuales continúan interesados en que no cambie el estatus actual. Desde luego, esa es la postura de las élites del sistema del arte, muy especialmente, de sus instituciones y del mercado, que se aferran a conservadoras posiciones patriarcales. Para los indiferentes el reto está en salir de la zona de confort.

La pioneras del movimiento feminista dentro del arte contemporáneo conquistaron un lugar dentro de la corriente principal para numerosas mujeres, así como la inclusión de disciplinas secularmente consideradas femeninas y, por tanto, con la categoría de meras artesanías decorativas, ahora empleadas por las creadoras como estandartes de su condición. Isabel Jiménez Arenas sugiere que son estrategias feministas de praxis terapéutica, de manera similar a cómo valora Catherine Clément los trances de histeria de las mujeres en determinadas ceremonias religiosas africanas. Sara Rivera Martorell usa el término estrategia con un sentido muy diferente en referencia a la exposición del MNCARS, De la revuelta a la posmodernidad (1962-1982), en concreto a la sección La revolución feminista, en una sala aparte, mientras que las mujeres estaban prácticamente ausentes en el resto: «una estrategia para salir del paso que hace que hoy el museo tenga una respuesta que dar a la pregunta que planteaba el Instituto de Investigaciones Feministas de la Universidad Complutense de Madrid en sus jornadas tituladas Museos y visibilización femenina, ¿Dónde están las mujeres? el pasado julio de 2012: en su habitación propia, a propósito de Virginia Woolf».

Helena Cabello y Ana Carceller en un decisivo trabajo sobre el asunto hablan de la ZONA F como aquel lugar de negociación en el que solo se cuestionan los estereotipos, sin limitaciones geográficas, formales o de género, donde las experiencias múltiples puedan cruzarse y enriquecerse mutuamente. En concreto, analizan los espacios, prácticas y recorridos de esta zona propuestos como nuevos modelos en la obra de artistas como Alicia Framis, Marina Núñez, Eija-Lisa Athila o Yasumasa Morimura.

Este es el marco de actuación que hemos de construir entre todos. En Lo femenino y lo sagrado, Caherine Clément y Julia Kristeva, debaten sobre lo sagrado en las mujeres, que en unos casos expresaría una revuelta instantánea, que atraviesa cuerpo y alma, propia de los oprimidos. Pero en otros tiempos/lugares las mujeres exhiben una dimensión de lo sagrado que está en el cruce transicional de la dualidad femenino-masculino presente en todos, en esa región residual de la gemelidad primigenia del ser humano. Solo activando esa zona de transicionalidad se accederá a lo sagrado. No es otra la propuesta que hace Verónica Ruth Frías en el contexto dual y sacro de la performance, que una vez más nos parece idóneo para formular toda una declaración de intenciones, múltiple y versátil plasmada de manera sutil e inteligente y con gran belleza y valentía, donde todo está sopesado y nada es gratuito. 


\section{Bibliografía}

BORJA-VILLEL, Manuel et al. (coord.) (2011), De la revuelta a la posmodernidad (1962-1982), Museo Nacional Centro de Arte Reina Sofía, Madrid.

BOURGEOIS, L. (2002), Destrucción del padre-Reconstrucción del padre, Síntesis, Madrid.

CABELLO, H. y CARCELLER, A., «ZONA F. Sujetos imprevistos (divagaciones sobre lo que fueron, son y serán)». En estudiosonline.net/ texts/femanism.html

CHADWICK, W. (2000), Mujer, arte y sociedad, Destino, Barcelona.

CHASTEL, A. (2005), El Renacimiento italiano (1460-1500), Akal, Madrid.

CLARK, K. (1998), El arte del Humanismo, Alianza, Madrid.

- (1998), Leonardo da Vinci, Alianza, Madrid.

CLEMENT, C. y KRISTEVA, J. (2000), Lo femenino y lo sagrado, Ediciones Cátedra, Universidad de Valencia/Instituto de la Mujer, Valencia.

CREIXEL, R.M., SALA, T.M., CASTAÑER, E. (2007), Espais Interiors. Casa i Art (des del segle XVIII al XXI), Universidad de Barcelona, Barcelona.

JIMÉNEZ ARENAS, I.M. (2006), La expresión plástica de Louise Bourgeois. Estrategias feministas para una praxis terapeútica, Universidad de Valencia, Valencia.

LIPPARD, L. (1976), From the Center. Feminist Essays on Women's Art, E. P. Dutton, Nueva York.

LOPEZ REJAS, J. (2000), «Sobre la deshumanización del arte», entrevista a Simón Marchán para El Cultural de El Mundo, Madrid, 8 de noviembre.

MAYAYO, P. (2007), Historias de mujeres, historias del arte, Cátedra, Madrid.

MORAZA, J.L. (1999), «Una relación imposible, real. Constructivismo y complicidad», comunicación presentada en el ámbito de las sesiones sobre artistas y feminismo convocadas con ocasión de la exposición de Martha Rossler en el MACBA de Barcelona. En estudiosonline.net/texts/femanismo.htm

NOCHLIN, Linda (1971), «Why Have There Been No Great Women Artists?», Art News, enero, pp. 22-39.

OCAMPO, V. (2016), Darse. Autobiografía y testimonios, Fundación Banco de Santander, Madrid.

ORTEGA Y GASSET, J. (1982), Paisaje con una corza al fondo (1927), Obras completas, vol. VI, Revista de Occidente, Madrid.

PANOFSKY, E. (1980), Idea. Contribución a la historia de la teoría del arte, Cátedra, Madrid.

POLLOCK, G. (2010), Encuentros en el museo feminista virtual, Cátedra, Madrid.

RIVERA MARTORELL, S. (2013), «El arte feminista y su exhibición: la musealización de un conflicto. El caso del Museo Nacional Centro de Arte Reina Sofía», Encrucijadas, vol. 190, n. ${ }^{\circ} 767$. Dedicado a «Mujer y periodismo en el siglo XIX. Las pioneras».

ROMERO TOBAR, L. (2014), «María Pilar Sinués, de la provincia a la capital del reino», «Mujer y periodismo en el siglo XIX. Las pioneras» ARBOR, Ciencia, Pensamiento y Cultura, vol. 190-767, DOl: http://dx.doi.org/10.3989/arbor.2014.767n3012.

W.AA. (1999), Louise Bourgeois. Memoria y arquitectura, Museo Reina Sofía, Madrid.

W.AA. (2004), Hannah Höch (1879-1978), Museo Reina Sofía, Madrid.

W.AA. (2016), Louise Bourgeois. Estructuras de la existencia: las celdas, Museo Guggenheim, Bilbao. 